from very severe abdominal pain, which had been continuous for the previous twenty-four hours. She was about three months gone in preguancy, and supposed herself to be miscarrying. There was no flooding, nor any pains resembling those of labour. On inquiry, it appeared that she had been removing on the preceding day, and had strained herself in lifting furniture. In the evening, she felt the pain come on. She said she had passed very little urine, but did not complain of any violent desire to urinate. The midwife had been with her, and had made frequent examinations. Becoming frightened, she sent for the priest, who sent for me.

After hearing the above particulars, I examined the abdomen, and found the bladder enormously distended. I drew off a large washhand-basinful of urine, containing several quarts. She expressed herself greatly relieved. I then made a vaginal examination, and my finger first touched the retroverted fundus of the uterus. With some difficulty I managed to reach the os, which was situated high up, and pressing against the neck of the bladder. The uterus seemed to be abont the size of one containing a three mouths' foetus. On close questioning, it appeared that she had not suffered at all from leucorrhoea or bearing-down pains, or lumbar or sacral pains, before the day of the removal. It seemed, therefore, that during her exertions the uterus must have become suddenly retroverted. As the bowels had not been opened for a couple of days, I thought it best to defer any attempts to replace the uterus until they should be relieved. She was ordered some black draught.

The next morning I was again sent for, as she had passed no urine during the night. The bowels had been freely opened. I again drew off the urine, and then introducing two fingers of my right hand into the vagina, by pressing on the fundus, I was able to replace the uterus. I passed a plug up behind the womb, and directed her to continue in bed for a few days. After this, she passed urine without any difficulty, and never had a bad symptom. The uterus remained in its normal position.

High-street, Deptford, 1859.

\section{COMPOUND DISLOCATION OF THE ULNA, WITH} FRACTURE OF THE RADIUS.

BY W ILLIAM SMITH, EsQ, M.R.C.S., SURGEON TO THE CHESTERTIEID MOSPITAX.

J. W-_ a strong, well-grown lad, aged fifteen, in the employ of the Wingerworth Iron Company, fell, whilst asleep, from the back of a cart, falling with one arm extended-the left-which in this manner received the combined shock and weight of the body.

I saw him immediately after the accident, and found the round head of the ulna, with the styloid process and about two inches of the shaft of the bone protruding through a longitudinal wound in the inner and front portion of the wrist. On more particular examination, I found the radius fractured about three inches above the carpus. The hand was everted. The ulna was not fractured.

Fixing the arm, I made extension from the hand, and reduced the dislocation with very listle difficulty. The external wound was brought together with adhesive plaster, a bandage and pair of splints carefully adapted to the arm, and the whole directed to be kept wet with spirit lotion. The case went on perfectly well, and the boy made a good recovery, without the slightest deformity of the carpus or forearm.

I believe this accident to be very rare; and that extreme modes of treating it have been advised may be seen by turning to Cooper's "Surgical Dictionary," page 45l, where the following remarks occur :-

"A protrusion of the small end of the ulna through the skin forwards must be excessively rare, awing to the strength of the ligaments, and the thickness of the integuments themselves, in this direction; but in the dislocation backwards, the ligaments make less resistance, and the skin is almost close to the bone, so that in this case the protrusion is more likely to happen. If the dislocation were compound, ought the end of the bone to be sawn off, or amputation performed? Dupuytren is in favour of immediately reducing the end of the ulna, and making free incisions for the relief of the tension and strangulation likely to ensme. He would not saw off the end of the nlna-much less 364 would he amputate. The free incisions, I think, would be early enough when the confinement of the inflamed parts by the fascia had actually come on, and threatened mischievous consequences."

March, 1859.

\section{ERYSIPELATOUS SORE-THROAT, OR DIPHTHERIA.}

By G. F. WILLS, EsQ., M.R.C.S., Crewkerne.

Erysipelatous inflammations have been unusually prevalent in this locality, and I have attended numerons cases of sore-throat with and without symptoms of catarrh, \&c. Eight or ten of these cases have been severe, but I select three which are unusual.

Two cases occurred in one family. A child, aged two years, in good health, had an attack of varicella. After four or five days I saw it, in consequence of a difficulty in swallowing. I found the mouth and throat much inflamed; severe febrile symptoms were present, and the pulse was very feeble and rapid. I also found that the vesicles had suddenly turned livid, and the fluid contained in them was dark. Wine and ammonia were given freely, and next day the throat was rather better, but the general condition of the child was not improved. The day after, I could not open the mouth sufficiently to see the throat. The mucous membrane of the nose was inflamed, and an offensive, semi-purulent discharge issued from the right nostril (as occurs in some bad cases of scarlatina). There was a hard swelling under the angle of each jaw; the lividity of the vesicles was greater; and the child rapidly sank. Two days afterwards a younger child, aged nine months, was taken ill with inflamed throat, \&c. Swellings appeared under each jaw, and this child also became rapidly worse, and died in about forty-eight hours. The presence of ehicken-pox in the eldest of the children is singular, and the unusual appearance presented by it shows the malignity of the accompanying dis. ease.

B. $B-$, aged twenty-five, complained, on the 28th of October last, of a cold, with sore-throat. This, by the use of saline aperients and sulphate-of-zinc gargle, became better, and by the 31 st he was well.

On Nov. 5th he was seized with rigors, followed by general pyrexia and sore-throat. The mucous membrane of the mouth and throat was inflamed; pulse 120, feeble. Calomel and hyoscyamus, and salines, were given, and a strong sulphate-ofzinc gargle.

6th. - Throat more painful and injected; tonsils fery red, with a slimy coating; pulse 120, feeble; great heat of skin. To have a succession of warm bran and mustard poultices round the throat; a tablespoonful of wine frequently; and three grains of sesquicarbonate of ammonia every four hours.

7th. - Throat less painful, but still very much inflamed and swollen; pulse 110, very feeble; tongue dry and brown. The patient appears to be sinking; great difficulty in swallowing. To have strong meat broth and eggs, and to increase the quantity of wine and ammonia.

Sth. - Erysipelas of forehead, ears, and neck: as this appeared, the throat became relieved, and is now much better and less inflamed; swallows freely; pulse 110, feeble. To continue the wine and soup, and to have one grain of quinine every four hours.

9th. -Throat much better; severe erysipelas of head and face. To continue the treatment.

13th. - Convalescent

Having left off the quinine and wine for two or three days, on the loth erysipelas of the neck and shonlders reappeared, but these being again given, it quickly went off, and he gradnally got well.

The above are the only cases occurring in my practice (and I believe in this locality) which have come up to the description of bad diphtheria. It appears to me that in the last case the inflammation in the throat was erysipelatous, and that when the system had power (if I may so speak) to throw off the disease from the more dangerous part, the throat was speedily relieved. 'I he internal inflammation subsided as external ery. sipelas appeared. This seems conclusive as to the nature of diphtheria, and as to the necessity of treating it similarly to a bad case of erysipelas. I should be glad to know the opinions 
of those who have had large experience in this frightful disease as to the local application of iodine. Its effects in external erysipelas are sometimes wonderful, and it would be worth trying in the prevalent inflammatory sore-throat.

March, 1859

\section{a eflitror}

OF THE PRACTICE OF

\section{MEDICINE AND SURGERY IN THR}

\author{
HOSPITALS OF LONDON.
}

Nulla est alia pro certo noscendi via, nisi quam plurimas et morborum et dissectionum historias, tam aliorum proprias, collectas habere $\epsilon$ inter se com parare.-Mobgagni. De Sed, et Caus. Morb., lib. 14. Proømium.

\section{UNIVERSITY COLLEGE HOSPITAL.}

STRUMOUS DISEASE OF THE KNEE.JOINT, WITH DEPOSITION OF TUBERCLE IN THE OSSEOUS STRTCTURES; EXCISION ; DEATH FROM ERYSIPELAS.

(Under the care of Mr. ERICHSEN.)

From the state of the patient on admission, as related in the case which follows, it is evident that in a little while the limb would have become so extensively involved as to hold out no other mode of relief than that of amputation of the thigh, with the risk at the same time of active disease in the lungs. As various plans of treatment had hitherto proved unavailing, and as circumstances were favourable, excision of the articulation was practised, with fair prospects of success. Unfortunately, however, erysipelas, which was prevailing in the wards, attacked the limb on the nineteenth day, up to which time everything was going on favourably. It did not yield to remedial measures, and the patient sank on the twenty-third day after the operation. For the notes of the case we are indebted to Mr. J. S. Wilkinson, house-surgeon to the hospital.

Mary Ann B-, aged thirty, single; parents are alive, and, with exception of her father, who is subject to rheumatism, her family enjoy good health. She was born and brought up in the country. She entered service as a servant, and has knelt a good deal on stone steps. Six years since she had pneumonia, which invalided her for twelve months. Four years and a half ago she had a catching pain in the left knee under the cap, accompanied with a crampy stiffness whilst walking, especially whilst going up and down stairs. This did not prevent her performing her ordinary work. Two years after, the joint inflamed and swelled much, occasioning continuous and excessive pain ; this was relieved by leeching, rest, and subsequent blistering, and the swelling decreased somewhat, so that she returned to her duties. Twelve months later she had another attack; the inflammation was less marked, although there was a good deal of pain and swelling, for which she was treated with benefit at Winchester Hospital. Twelve months since, startings at night began, and blisters were applied with advantage. She then continued under surgical treatment $n p$ to the time of admission. Until within the last eight months the patient has not felt pain in the knee, except whilst exercising it; since then it has prevented her walking, and if she stood for any time the joint became puffy, as also the leg and foot; this subsided on reclining. During the night she would awake with pain, and if the foot were knocked, the pain was excruciating. She has been losing flesh fast, especially of late.

On admission, December 29 th, 1858 , the patient seems careworn, much emaciated, and has altogether a tuberculous aspect; has a bad appetite and a slight cough, but the chest reveals no physical signs of disease. The diseased knee is semi-flexed, rounded, and full, the outlines of the various points being barely perceptible to the eye or touch; it measures fourteen inches and a half in circumference over patella (sound knee eleven and $a$ half), and the skin and tissues are thickened, nedematons, and resisting, and convey a semi-elastic feeling. Manipulation causes much pain, especially when gliding the opposed articular surfaces of the femur and tibia over one another, which is readily permitted from the laxity of the ligaments and capsule; this elicits no grating. There is great pain when pressure is applied over the tuberosity of the tibia, and the outer boundary of the joint is tender and inflamed. The thigh is emaciated, and the leg and foot oedematous, contrasting much with the meagre limb of the opposite side. The knee was fixed in leather splints, and the patient was put on a tonic of quinine and iron.

Jan. 5th, 1859.- Her general health is much better; appetite improved, and there is no pain in the knee, except when the splints are taken off, or towards night when she drops off to sleep. Mr. Erichsen has decided upon resecting the joint.

Operation.-The patient being put under the influence of chloroform, and placed on the operating-table, the knee was well flexed to stretch the tissues in front of it. A transverse incision was made from condyle to condyle over the lower part of the patella, which was dissected out; in so doing a quantity of liquid, softened-down, pultaceous débris escaped. The articular cartilages were ulcerated to a great extent, and the ends of the bones exhibited cavities containing softening tubercle. The lower end of the femur was removed just above the condyles, as was also the upper end of the tibia to the depth of half an inch. The freshly-sawn surface of the femur was healthy, but that of the tibia presented three or four largish spots of tubercular deposit, which were gouged out. Three ressels required ligaturing, and the edges of the wound were brought together by three sutures. The wound was kept well covered with water-dressing. On recovering from the effects of the chloroform, she had thirty minims of laudanum. The pain continuing, twenty more were administered at ten P.M. Pulse 95.

After the operation, the patient went on well up to the 24th, when she unfortunately caught erysipelas, that affection bein very rife at the time. This subsided, leaving her weak and unable to bear the pain of having her splints changed (which was absolutely necessary) without chloroform. On anæsthesia passing away, the patient was very sick, and continued retching up to the afternoon of the 28th, in spite of all the remedies tried. She had now small quantities of brandy at short in tervals, and a brandy-and-egg enema, with beef-tea, in hopes of rallying her, but she gradually sank, and died at eight P.M.

The following were the means adopted in order to ensure the highly essential points of keeping the cut ends of the bones in close apposition, and preventing their movement:-

Immediately after the operation, the limb was bandaged to a well-padded straight splint, running up the back of the leg and thigh as high as the tuber ischii, with a foot-piece at right angles.

When the sutures were removed (10th), the edges of the wound, which were for the most part united, were supported. by three strips of plaster.

12th. -The apparatus having become loose, it was re-applied, with the addition of two broad pieces of gutta percha, lined with a thin layer of cotton wool, arched, the one over the front of the leg, and the other over the front of the thigh, and further support was given by a strip of gutta percha on either side of the knee; but although this answered admirably at first, in the course of a few days the gutta percha yielded to the heat of the limb, and allowed displacement of the bones.

20th. - To obviate this, the following alterations were made in the splint:-The gutta percha was used as on the last oceasion, but in addition it was embraced by a pair of wooden flaps ( 2 in. by 13 in.), hinged on to the back splint on either side of the leg, and a similar pair ( 3 in. by 9 in.) on either side of the thigh, thus affording an unyielding support to the limb, keeping the ends of the bones in perfect apposition, and preventing the slightest movement of them.

To facilitate dressing the wound, and allow free exit to the discharges without disturbing or soiling the apparatus, a piece of gutta percha, about fifteen inches long, was bandaged on either side of the knee, external to the general splint.

\section{CHARING-CROSS HOSPITAT.}

EXCISION OF THE ANKLE-JOINT, IN A CHILD, FOR EXTENSIVE DISEASE; RECOVERY, WITH A USEFUL FOOT.

(Under the care of Mr. HANCOCK.)

WHILST the knee and the hip in the lower, and the elbow and the wrist in the upper, extremity have been excised for disease on numerous occasions, the ankle and the shoulder would seem to be remarkably exempt from this proceeding. That this should be so with regard to the shoulder need not 